\title{
Correlation between the single, high dose of ingested baclofen and clinical symptoms
}

\author{
Jacek Sein Anand ${ }^{1,2}$, Maciej Zając ${ }^{1,2}$, Wojciech Waldman ${ }^{1,2}$, Andrzej Wojtyła ${ }^{3}$, \\ Przemysław Biliński ${ }^{3}$, Barbara Jaworska-Łuczak ${ }^{4}$ \\ ${ }^{1}$ Department of Clinical Toxicology, Medical University of Gdansk, Poland \\ 2 Pomeranian Center of Toxicology, Poland \\ ${ }^{3}$ Department of Medicine, Higher Vocational State School in Kalisz, Poland \\ ${ }^{4}$ Office for Registration of Medicinal Products, Medical Devices and Biocidal Products, Warsaw, Poland
}

Sein Anand J, Zając M, Waldman W, Wojtyła A, Biliński P, Jaworska-Łuczak B. Correlation between the single, high dose of ingested baclofen and clinical symptoms. Ann Agric Environ Med. 2017; 24(4): 566-569. doi: 10.5604/12321966.1230735

\section{Abstract}

Introduction and Objectives. Baclofen is a drug used mainly to treat muscle spasticity. Its overdose can lead to lifethreatening clinical symptoms, including acute respiratory failure requiring mechanical ventilation. The aim of this study was to assess the prevalence of selected clinical symptoms associated with baclofen poisoning comparing to an ingested dose.

Materials and method. 60 cases of oral baclofen poisoning were analyzed. Gender, age distribution, and correlation between the dose of ingested baclofen were studied, as well as and following clinical parameters: degree of altered consciousness, heart rate, blood pressure, presence of acute respiratory failure, duration of mechanical ventilation, and presence of psychotic symptoms.

Results. The study found statistically significant correlations between dosage of ingested baclofen and presence of acute respiratory failure, as well as duration of mechanical ventilation. No statistically significant correlations were found between the dose of ingested baclofen and presence of hypertension, bradycardia, acute psychotic symptoms, or level of consciousness disturbance. However, it was found that patients who suffered from hypertension, bradycardia, and altered mental status ingested a larger dose of baclofen.

Conclusions. There is a statistically significant correlation between the dose of ingested baclofen and the presence of acute respiratory failure, and duration of mechanical ventilation. Patients who have taken a single dose of baclofen of $200 \mathrm{mg}$, or higher, should be managed in centres able to provide continuous monitoring of life functions. Those with a higher level of a single dose of baclofen ingestion (>500 mg), should be hospitalized in a Toxicology Unit or Intensive Care Unit able to provide airway support and mechanical ventilation.

\section{Key words}

acute poisoning, acute respiratory failure, baclofen, mechanical ventilation

\section{INTRODUCTION}

Baclofen (p-chlorophenyl-gamma-hydroxybutyrate) is an analog of $\gamma$-hydroxybutyric acid (GABA), an agonist of $\mathrm{GABA}_{\mathrm{B}}$ receptors. It reduces muscle spasticity by inhibiting neurotransmission in the brain and spinal cord. The drug is used in the treatment of many neurological disorders causing increased muscle spasticity, such as multiple sclerosis, brain, and spinal cord injuries [1].

A daily oral dose of baclofen is determined individually and is usually $30-75 \mathrm{mg} /$ day. The drug is rapidly absorbed from the gastrointestinal tract, reaching peak plasma concentrations after 2 hours. $30 \%$ of the drug is bound to plasma proteins and is partially metabolized in the liver $(10-15 \%)$ and then removed by the kidneys $[2,3,4]$.

Presently, baclofen in relatively high dose is used in the management of alcohol dependence and withdrawal syndrome $[5,6]$. Recreational use of baclofen as a psychoactive substance has also been reported $[7,8]$.

Address for correspondence: Jacek Anand, Department of Clinical Toxicology, Medical University of Gdansk Pomeranian Center of Toxicology.

E-mail: JACEK.ANAND@GMAIL.COM

Received: 18 February 2014; accepted: 29 September 2015; first published on January 2017

\section{OBJECTIVE}

The aim of the study was to assess the relationship between the ingested dose of baclofen and selected clinical symptoms. According to the best of the authors' knowledge, this study is the largest to-date concerning baclofen poisoning.

\section{MATERIALS AND METHOD}

The study involved 65 patients with acute oral baclofen poisoning who were treated in Toxicology Center in Gdansk, Poland, between 1996-2004 and 2009-2012. 60 patients 42 women and 18 men, aged 14-58 (mean 22) years, were involved in the statistical analysis. Five patients were excluded from the study: 3 patients with hypotension, 1 patient who ingested an extremely high dose of baclofen (5000 mg), and 1 patient who had supraventricular tachycardia.

The dose of ingested baclofen were determined based on patient's anamnesis, interview with the family and empty packages of drugs. All analyzed patients were intoxicated only with baclofen.

The following were analyzed: level of altered mental status defined by the Matthew-Lawson coma scale (0-IV), heart rate (bradycardia $<60$ beats/min, tachycardia $>100$ 
beats/min), blood pressure (hypotension $<90 / 60 \mathrm{mmHg}$, hypertension $>140 / 90 \mathrm{mmHg}$ ), presence of acute respiratory failure (ARF), duration of mechanical ventilation (DMV), and presence of acute psychotic symptoms. ARF was defined as airway obstruction, need of intubation, respiratory rate $<10$ breaths/min, $\mathrm{PaO}_{2}<60 \mathrm{mmHg}$ (with oxygen supply), $\mathrm{PaCO}_{2}>50 \mathrm{mmHg}$.

In order to identify relationships between the dose of ingested baclofen and clinical symptoms, 2 statistical models were used: Generalized Regression Model and Analysis of Variance model.

Retrospectively, all patients gave informed consent to participate in the study.

\section{RESULTS}

The studied group comprised 60 patients -42 women aged 14-58 (mean 31) years and 18 men aged 15-53 (mean 26) years. The age of patients in the entire group ranged from 14-58 (mean 29) years. Female to male ratio was $70: 30 \%$. The dosage of ingested baclofen ranged from 50-1,500 (mean 435) $\mathrm{mg}$. Among the females, the dosage was from $50-1,500$ (mean 408) $\mathrm{mg}$, and among the males from 200-1,500 (mean 498) $\mathrm{mg}$.

Collected data showed a statistically significant correlation between the dose of ingested baclofen and the presence of ARF in both groups.

Figure 1 presents the relationship between the presence of $\mathrm{ARF}$ and the dose of ingested baclofen. ARF was observed in 24 patients ( $40 \%$ of cases) - 13 women and 11 men, all of whom needed endotracheal intubation. The mean dose of ingested baclofen in the group with ARF was $612.5 \mathrm{mg}$, while in the group without ARF - $316 \mathrm{mg}$.

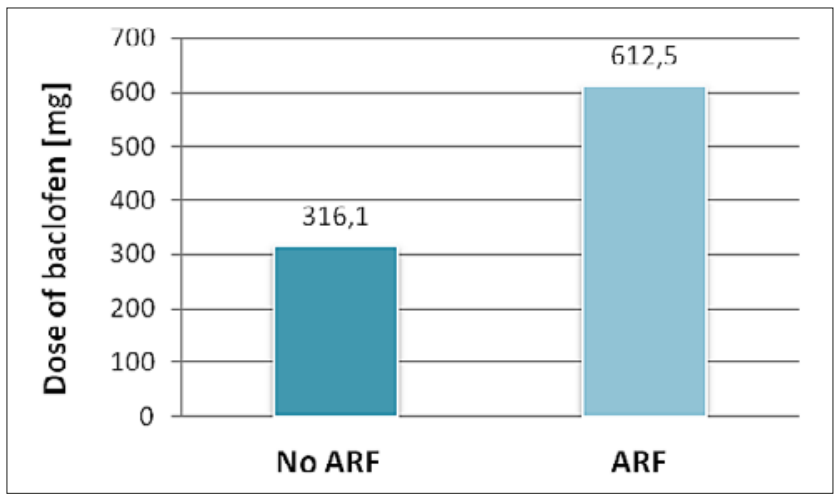

Figure 1. Acute respiratory failure (ARF) according to drug dose

Mechanical ventilation was required in 21 (35\%) patients - 10 women and 11 men. Figure 2 shows the correlation between the dose of the drug and duration of mechanical ventilation (DMV). Every $100 \mathrm{mg}$ of ingested baclofen increased DMV, on average, for 3.43 hours.

Figure 3 shows the mean values of ingested baclofen and the depth of coma as defined by the Matthew-Lawson scale $(0-I V)$. A statistically significant correlation was observed between the dose of baclofen and advanced IV degree of coma in the females, but not in the group of males. It was also noticed that the average dose of baclofen in the group of patients with IV degree of coma was significantly higher than that in the group of patients with 0 -III degree of coma (625

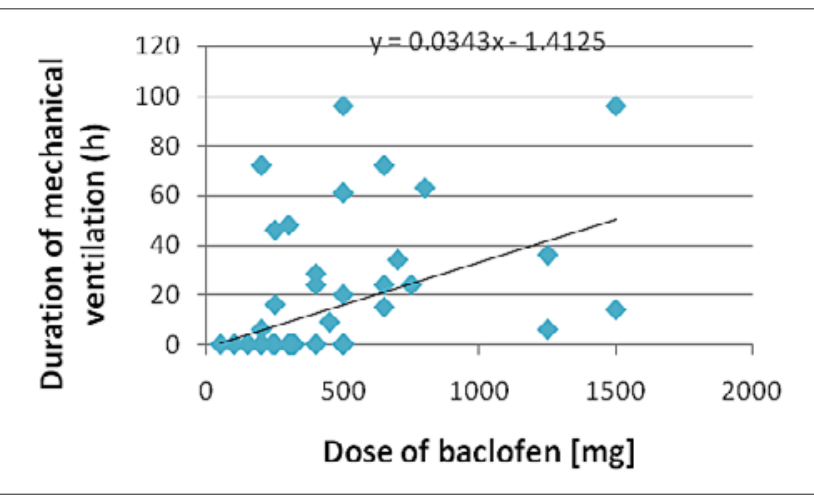

Figure 2. Dose of baclofen and duration of mechanical ventilation (DMV)

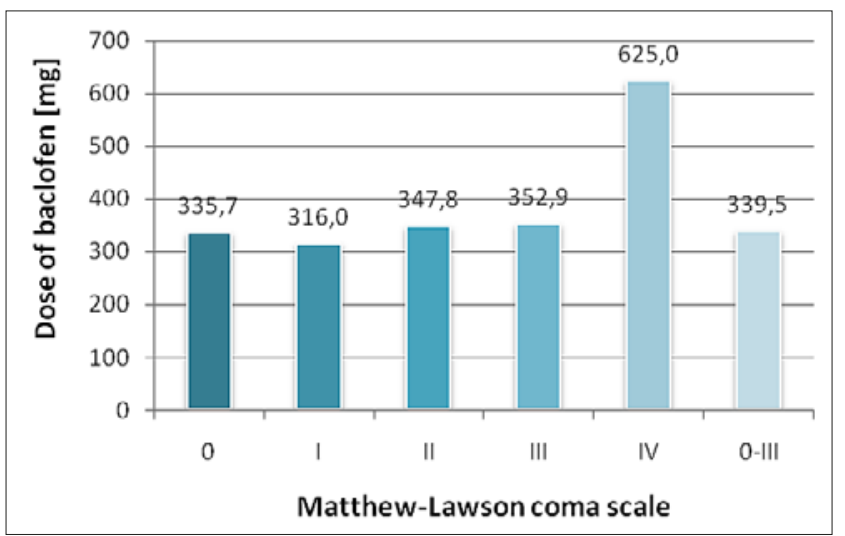

Figure 3. Average dose of ingested baclofen and depth of coma according to the in Matthew-Lawson scale

vs. $340 \mathrm{mg}$ ). Trends between the dose of ingested baclofen and the depth of coma are illustrated in Figure 4. This suggests the existence of a general correlation, but the size of the presented sample does not allow a clear confirmation of this hypothesis.

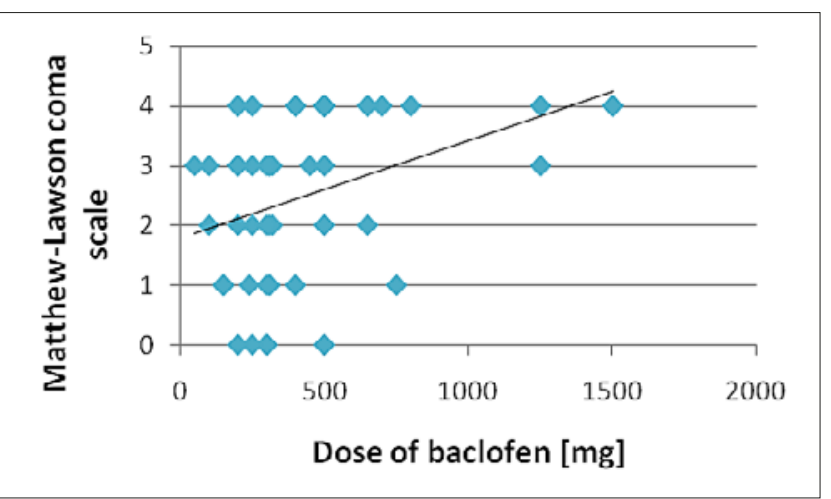

Figure 4. Trends between dose of ingested baclofen and depth of coma

Bradycardia was observed in 24 (40\%) patients - 14 women and 10 men. There was no statistical correlation between the dose of the drug and bradycardia; however, mean doses were higher in the group of patients with bradycardia than in the group with normal heart rate (556 vs. $354 \mathrm{mg}$ ). With the exception of one patient with supraventricular tachycardia, which was excluded from statistical analysis, no other subjects with tachyarrhythmia were observed.

Hypertension was noticed in 21 (35\%) cases of baclofen intoxication - 15 women and 6 men. When gender was 
considered, a correlation was observed between the dose of ingested baclofen and hypertension only in the group of women. Alternatively, male patients experienced hypertension at lower doses of the ingested drug. However, a statistically significant correlation was found between the dose of admitted baclofen and hypertension, and the presence of ARF symptoms for both the male and female groups. These relationships are illustrated in Figure 5.

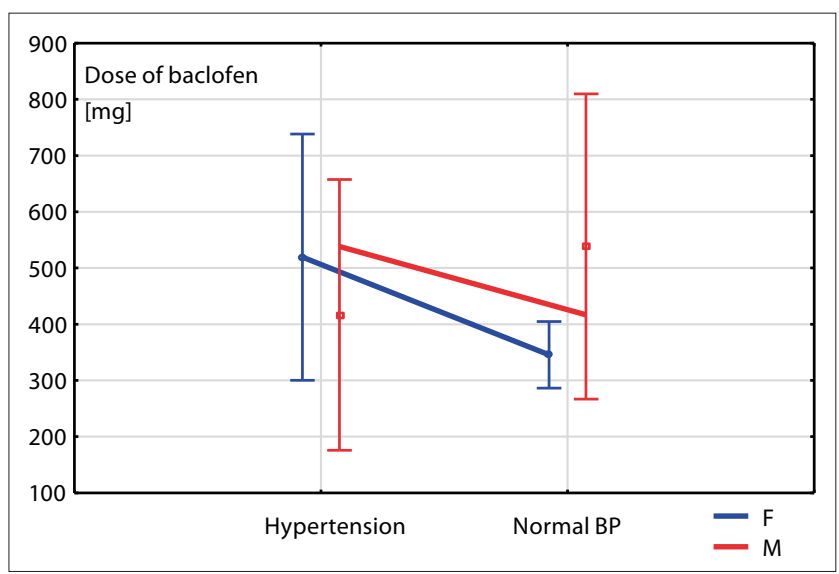

Figure 5. Correlation between dose of baclofen and blood pressure in males and females groups

Psychosis was observed only in 8 (13\%) cases - 4 women and 4 men. According to the presented data, presence or absence of psychosis did not correlate with the dose of ingested baclofen.

\section{DISCUSSION}

Peaslack first reported oral baclofen poisoning in 1972 [9]. Since then, there have been several cases or case series involving up to 23 patients $[1,7,10,11,12,13]$. Presently, the rate of baclofen intoxications has increased $[12,13]$, mainly because of its off-label use in alcohol dependent patients who much more often perform suicidal attempts [12].

The most common clinical symptoms of baclofen overdose include altered level of consciousness, coma, acute respiratory failure, cardiac arrhythmias, and hypertension $[1,7,10]$. Although fatal outcomes are rare, some authors suggest that such poisonings are more severe than other overdoses, and life-threatening complications are more common $[11,13$, 14]. Pommier et al. revealed that baclofen poisoning patients had longer DMV and ICU stay, compared to non-baclofen poisoning cases [13].

Plasma concentration correlates with the severity of baclofen poisoning, especially in the first day, and might be useful in making a decision concerning admission to a Toxicological or Intensive Care Unit providing more aggressive treatment, including mechanical ventilation or an extracorporeal elimination method [7]. On the other hand, several authors have noted that measurement of baclofen blood level in the late stage of intoxication might be misleading, because clinical symptoms may be present despite subtherapeutic level of baclofen $[7,8]$. This is probably due to its lipophilic properties, and penetration of the drug into the brain tissue [15]. Unfortunately, in the majority of Polish and European hospitals, there is no quick assessment method to analyze the baclofen plasma concentration.

Clinicians have observed that the dose of ingested baclofen might, to some extent, be a relatively good factor which can help to make decision about the place and method of treatment of baclofen intoxicated patients. Pommier et al. noticed that this poisoning correlate with the ingested dose of drug [13]. Leung et al. assumed also that clinical symptoms of intoxication might be more (dose of baclofen $>200 \mathrm{mg}$ ) or less serious (dose of baclofen $<200 \mathrm{mg}$ ), depending on the dose ingested by the patient $[10,13]$.

In the presented study, ARF, which is a clinically very important factor, had the strongest correlation with the dose of baclofen. Leung et al. also showed the important relationship between the dose of ingested baclofen and the presence of ARF [10]. In his study, 7 of 13 patients who ingested at least $200 \mathrm{mg}$ of baclofen required mechanical ventilation. In the current analysis, ARF was observed even with relatively minor doses. It is important that mechanical ventilation is used in all cases of poisonings of at least $500 \mathrm{mg}$ of baclofen. Also, DMV correlated with the dose of drug. With each $100 \mathrm{mg}$ of ingested baclofen, mechanical ventilation was prolonged for approximately 3.43 hours. Other analyzed correlations were not as strong. However, in the current study, a statistically significant correlation was observed between hypertension and dose of ingested baclofen in the group of women. Leung et al. observed hypertension in $69 \%$ of cases who ingested a higher dose ( $>200 \mathrm{mg}$ ) of baclofen, but they did not analyzed the gender [10]. On the other hand, Franchitto et al. reported hypertension in only 4 of 12 cases [12].

Although bradycardia did not correlate with the dose of ingested baclofen, it could be a helpful diagnostic sign which was observed in $40 \%$ of all cases in the presented study.

Coma was a frequent occurrence in the group of patients who ingested a high dose of baclofen. There are a few cases reported in the medical literature where coma and areflexia were presented to such an extent that brain death was suspected untill the time baclofen poisoning was diagnosed [16]. In the current study, no statistically significant correlation was found between the dose of ingested baclofen and grades of Matthew-Lawson coma scale. The authors of the current study are in agreement with Leung et al., that severe alteration of consciousness is more frequent in the group of patients who ingested high dose (>200 mg) of baclofen [10]. Pommier et al. noticed in their group low Glasgow Coma Scale in a baclofen poisoning group, but he did not compare it with the dosage of baclofen [13].

In the presented study, psychosis was a rare (13\%) symptom of poisoning, and did not correlate with the dose of the ingested drug. Perry et al. also found no correlation between the ingested dose, nor the concentration of baclofen in the blood and the presence of psychosis. Psychosis was observed late in the course of intoxication and also occurred when the blood level concentration was even below therapeutic levels [7].

Leung et al. reported delirium in $62 \%$ of his patients who ingested a high dose (>200 mg) of baclofen [10]. In the opinion of the authors of the current study, however, acute psychosis after baclofen poisoning does not depend on its dose, and it is rather a 'withdrawal' symptom. Therefore, chronic baclofen therapy, for example, should not be discontinued abruptly, as rapid cessation may lead to development of severe withdrawal symptoms $[1,17,18]$. 
Treatment of baclofen intoxication is mainly supportive. The patients in the presented study were successfully treated with gastric lavage, charcoal, intensive supportive treatment, and mechanical ventilation. Antidotes like flumazenil and/ or physostigmine are not very effective for baclofen overdose $[19,20]$. Atropine can normalize heart rate in the case of bradycardia [21]. There are conflicting reports regarding baclofen elimination and its half-life time $[9,11]$. According to Ghose et al., baclofen plasma half-life time is 3.5 hours in therapeutic doses, and in the case of overdose, there is a 5 -fold increase of plasma half-life [9]. In patients with endstage renal disease (ESRD), the half-life of baclofen is also significantly increased, even with therapeutic doses $[4,22]$. Hemodialysis in such patients resulted in a good clinical outcome $[4,22]$. Clearance for baclofen in patients who underwent intermittent haemodialysis (iHD) varied between $0.195 / \mathrm{h}-0.336 / \mathrm{h}[4,23,24]$. The use of $\mathrm{iHD}$ in patients with renal failure is considered the treatment of choice. Presently, there are encouraging reports of the use of haemodialysis in baclofen poisoning patients with normal renal function $[24,25]$. Further research should focus on extracorporeal baclofen elimination methods, and utility of determination of baclofen plasma concentration.

\section{CONCLUSIONS}

There is a statistically significant correlation between the dose of ingested baclofen and the presence of acute respiratory failure, and duration of mechanical ventilation. Patients who have taken a single dose of baclofen of $200 \mathrm{mg}$, or higher, should be managed in centres able to provide continuous monitoring of life functions. Those with a higher level of a single dose of baclofen ingestion (>500 mg), should be hospitalized in a Toxicology Unit or ICU able to provide airway support and mechanical ventilation.

\section{REFERENCES}

1. Dario A, Tomei G. A benefit-risk assessment of baclofen in severe spinal spasticity. Drug Saf. 2004; 27(11): 799-818.

2. Anderson P, Noher H, Swahn CG. Pharmacokinetics in baclofen overdose. J Toxicol Clin Toxicol. 1984; 22(1): 11-20.

3. Ghose K, Holmes KM, Matthewson K. Complications of baclofen overdosage. Postgrad Med J. 1980; 56(662): 865-867.

4. Wu VC, Lin SL, Lin SM, Fang CC. Treatment of baclofen overdose by haemodialysis: a pharmacokinetic study. Nephrol Dial Transplant. $2005 ; 20(2)$ : 441-43.
5. Addolorato G, Leggio L, Abenavoli L, Agabio R, Caputo F, Capristo E, et al. Baclofen in the Treatment of Alcohol Withdrawal Syndrome: A Comparative Study vs Diazepam. Am J Med. 2006; 119(3): 276. e13-276.e18.

6. Howland RH. Baclofen for the treatment of alcohol dependence. J Psychosoc Nurs Ment Health Serv. 2012; 50(10): 11-14.

7. Perry HE, Wright RO, Shannon MW, Woolf AD. Baclofen overdose: Drug experimentation in a group of adolescents. Pediatrics. 1998; 101(6): 1045-1048.

8. Weisshaar GF, Hoemberg M, Bender K, Bangen U, Herkenrath P, Eifinger F, et al. Baclofen intoxication: a "fun drug" causing deep coma and nonconvulsive status epilepticus - a case report and review of the literature. Eur J Pediatr. 2012; 171(10): 1541-1547.

9. Paeslack V. Lioresal in the treatment of spinal spasticity. Postgrad Med J. 1972; 48(Suppl 5): 30-34.

10. Haubenstock A, Hruby K, Jäger U, Lenz K. Baclofen (Lioresal) intoxication - report of 4 cases and review of the literature. J Toxicol Clin Toxicol. 1983; 20(1): 59-68.

11. Leung NY, Whyte IM, Isbister GK. Baclofen overdose: defining the spectrum of toxicity. Emerg Med Australas. 2006; 18(1): 77-82.

12. Franchitto N, Pelissier F, Lauque D, Simon N, Lançon C. SelfIntoxication with Baclofen in Alcohol-Dependent Patients with Coexisting Psychiatric Illness: An Emergency Department Case Series. Alcohol Alcohol. 2014; 49(1): 79-83.

13. Pommier Ph, Debaty G, Bartoli M, Viglino D, Carpentier F, Danel V et al. Severity of Deliberate Acute Baclofen Poisoning: A Nonconcurrent Cohort Study. Basic Clin Pharmacol Toxicol. 18, Oct. 2013; doi: 10.1111/ bcpt.12161.

14. Fraser AD, MacNeil W, Isner AF. Toxicological analysis of a fatal baclofen (Lioresal) ingestion. J Forensic Sci. 1991; 36(5): 1596-1602.

15. Lipscomb DJ, Meredith TJ. Baclofen overdose. Postgrad Med J. 1980; 56(652): 108-109.

16. Sullivan R, Hodgman MJ, Kao L, Tormoehlen LM. Baclofen overdose mimicking brain death. Clin Toxicol. 2012; 50(2): 141-144.

17. Pizon AF, LoVecchio F. Reversible Cardiomyopathy Complicating Intrathecal Baclofen Withdrawal: A Case Report. J Med Toxicol. 2007; 41: 187-189.

18. Watve SV, Sivan M, Raza WA, Jamil FF. Management of acute overdose or withdrawal state in intrathecal baclofen therapy. Spinal Cord. 2012; 50: 107-111.

19. Byrnes SMA, Watson GW, Hardy PAJ. Flumazenil: An unreliable antagonist in baclofen overdose. Anaesthesia. 1996; 51(5): 481-482.

20. Saltuari L, Baumgartner H, Kofler M, Schmutzhard E, Russegger $\mathrm{L}$, Aichner F, et al. Failure of physostigmine in treatment of acute severe intrathecal baclofen intoxication. N Engl J Med. 1990; 322(21): 1533-1534.

21. Ferner RE. Atropine treatment for baclofen overdose. Postgrad Med J. 1981; 57(671): 580-581.

22. Bassilios N, Launay-Vacher V, Mercadal L, Deray G. Baclofen unerotoxicity in a chronic haemodialysis patient. Nephrol Dial Transplant. 2000; 15(5): 715-716.

23. Brvar M, Vrtovec M, Kovac D, Kozelj G, Pezdir T, Bunc M. Haemodialysis clearance of baclofen. Eur J Clin Pharmacol. 2007; 63(12): 1143-1146.

24. Hsieh MJ, Chen SC, Weng TI, Fang CC, Tsai TJ. Treating baclofen overdose by hemodialysis. Am J Emerg Med. 2012; 30(8): 1654.e5-1654. e7.

25. Dias LS, Vivek G, Manthappa M, Acharya RV. Role of hemodialysis in baclofen overdose with normal renal function. Indian J Pharmacol 2011; 43(6): 722-723. 